\title{
Gallbladder cancer stem cell markers: An updated brief review
}

\author{
A.N Srivastava ${ }^{1}$, Naseem Fatima ${ }^{2 *}$ and Vijay Kumar ${ }^{3}$ \\ ${ }^{1}$ Director Research, Consulting Professor, Department of Pathology, Era's Lucknow Medical College \& Hospital, Lucknow, India \\ 2*Research Assistant, Department of Pathology, Era's Lucknow Medical College \& Hospital, Lucknow, India \\ ${ }^{3}$ Professor, Department of Surgical Oncology, King George's Medical University, Lucknow, India
}

\begin{abstract}
Gallbladder cancer is the most aggressive gastrointestinal tract cancer. It is a leading cause of cancer deaths in north india. The symptoms of gallbladder cancer are non specific, patients are diagnosed at very last stage, as a result, most of the patients die within 6 months of the disease, and hence the average 5 -year survival is low to $5 \%$. Cancer stem cell hypothesis provides an important cellular mechanism to understand the abnormal behavior exhibited by the tumors. Therefore, cancer stem cell markers may serve as novel therapeutic targets as well as diagnostic or prognostic markers in gallbladder cancer. In this review, we provide an overview of gallbladder cancer with the aim of concerning the role of cancer stem cell marker in the signaling pathways implicated along with the significant role of cancer stem cell markers in gallbladder cancer.
\end{abstract}

\section{Introduction}

Gallbladder cancer (GBC), the major type of gastrointestinal cancer, is one of the most common types of malignancy, and ranked as the third leading cause of cancer death in North India $(21.5 / 100,000)$. $[1,2]$. There are no specific sign and symptoms in the early stage of the disease; therefore it is diagnosed at its advanced stage. Poor prognosis shows low survival. It can be cured only if it is diagnosed before it is spread, and can be removed by surgery. Gallbladder cancer is a disease in which malignant (cancer) cells develops in the tissue of gallbladder, later spread to other parts of the body (metastasis where-in cells break away from where they began and travel through lymph system and blood). Gallbladder cancer spreads to the liver; they are actually gallbladder cancer cells. It may also spread to surrounding tissues and organs, through the abdominal cavity or distal part of the body.

Scientists have found several risk factors that make a person more likely to develop gallbladder cancer. Cholecystitis is also now seen often in much younger age group persons in North India. Chronic inflammation and dysplasia have been proposed to explain the association of gallstones and cancer. Besides, several other factors have also been proposed the critically and one of the views is of the presence and activation of Cancer Stem Cells (Figure1).

\section{Concepts of stem cells and cancer stem cells}

Stem cells play many vital roles in our body, they are long lived, uncommon, mother cells which have ability to self renew. [3] Self renewal, one of the defining characteristics of the stem cells, is a cell division in which one or both of the resulting daughter cells remains undifferentiated, retaining the ability to give rise to another stem cell with the same capacity to proliferate as the parental cell [4] and have the potential to become any type of cell, they can become cells of the blood, heart, bones, skin, muscles, brain etc.[5]. When mutated, they can potentially become cancer stem cells (CSCs). There are two types of stem cells: Pluripotent Stem Cells (PS cells) are the type of stem cells present in embryos that helps babies grows within the womb. Recent research has enabled scientists to derive pluripotent cells from adult human skin cells. These are termed induced pluripotent stem cells or iPS cells [6]. Fetal stem cells are obtained from tissues of a developing human fetus and are generally obtained after an abortion. These stem cells are not immortal but have a high level of division and are multipotent. Every organ or tissue in the body contains a small number of cells called Adult stem cells; they ensure a continuous supply of new cells to replace old cells that are destroyed [7].

\section{Role of cancer stem cells in tumorigenesis}

Organs develops from stem cells, same as tumors also consists of rapidly proliferating cells and also represent a disparate collection of abnormal cells with dissimilar phenotypes [8]. These abnormal cells are believed to be originated from a self -renewing population that gives rise to discriminatory progenitor cells. Cancer stem cell research hypothesized that the mutation in stem cell niche population during development results in the reproduction of mutated daughter cells, these cells are very much closer to become tumor and their number increase the chance of cancerous mutation.

Today, increasing evidence has confirmed that the cancers consist of small population of cancer stem cells or tumor initiating cells (TIC) which are considered being responsible for the recurrence of cancer and metastasis. It has been reported by the researchers that the CSCs are present in multiple solid tumors, in breast tumors [9], brain [10],

Correspondence to: Naseem Fatima, Research Assistant, Department of Pathology, Era's Lucknow Medical College \& Hospital, Lucknow, E-mail: naseemfatima.fatima@gmail.com

Key words: gallbladder cancer, gallstone, cancer stem cell markers

Received: January 07, 2017; Accepted: March 03, 2017; Published: March 06, 2017 


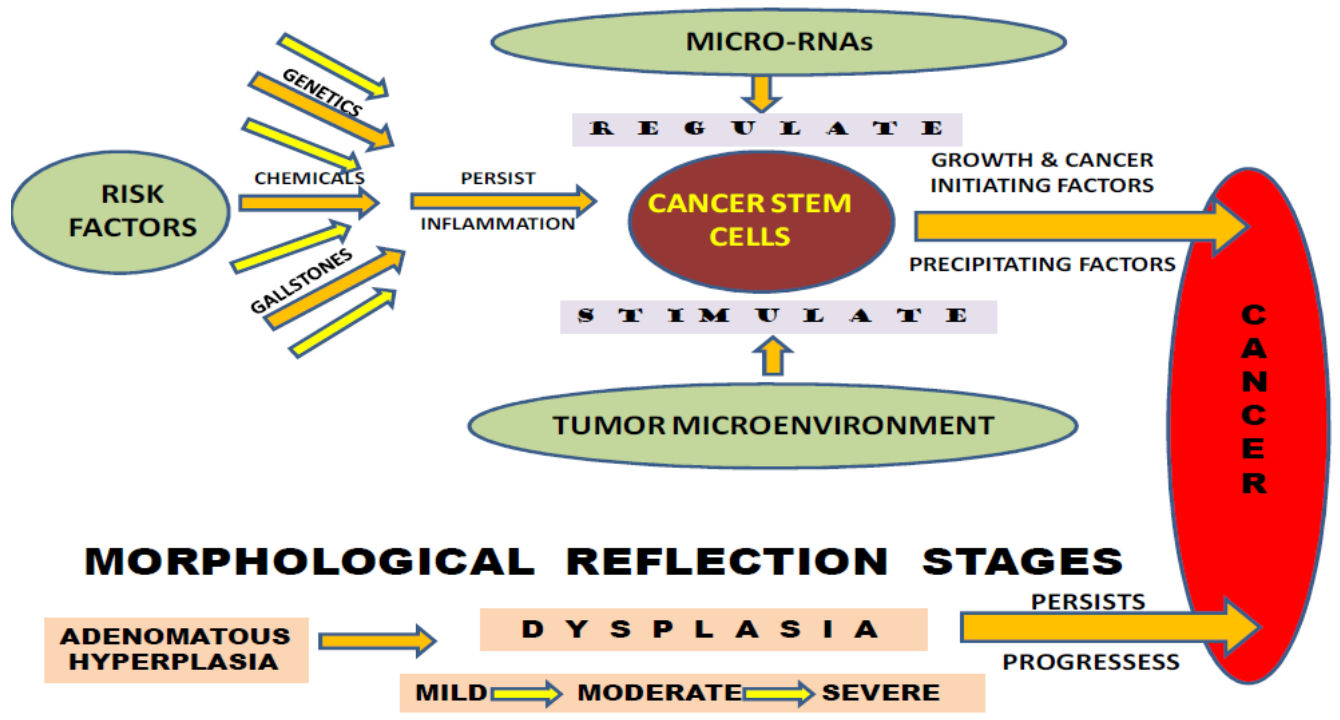

Figure 1. Risk factors responsible for the activation of cancer stem cells leading to gallbladder cancer progression.

prostate [11], colon cancer [12, 13], lung [14] and HNSCC [15] and therefore it is considered as one of the major cause of death.

The concept of CSCs is derived from the similarities that exist between normal stem cells and CSCs. The signaling pathways utilized by both normal stem cells and CSCs overlap and are based on embryonic signaling pathways which allow self-renewal. Advancement of knowledge in the concept of Cancer Stem Cells and their encouraging results suggest new directions in the treatment of cancer as they are thought to be responsible for tumor initiation, progression, therapy resistance, relapse and metastasis [16]. The well accepted CSC markers of are CD44, CD24, CD133, CD166 and EpCAM and a few more [17] and most of them are also reported in Gall Bladder Cancer.

\section{Common important cancer stem cell markers of gall-} bladder cancer

\section{CD24}

$\mathrm{CD} 24$ is a small cell surface protein, has emerged as a novel prognostic factor in human cancers [18] and is an important marker of malignancy. It is associated with poor prognosis in gall bladder carcinoma. Its expression has been immunohistochemically examined, has been reported as an important prognostic markers in gallbladder cancer along with its positive correlation with tumor histological grading and pT sataging. Furthermore, the CD24 antigen represents an attractive target for specific therapies with monoclonal antibodies in patients with CD24-overexpressing gallbladder carcinoma, so the detection of CD24 may help clinicians select patients likely to benefit from novel molecular therapies [19]. Song et al. have reported that NDRG2 down-regulation or CD24 up-regulation is an important feature of GBC. A combined detection of NDRG2/CD24 co-expression may benefit us in prediction of the prognosis in GBC [20].

\section{CD133}

CD133 (also known as Prominin-1 or AC133), a transmembrane pentaspan protein, was initially described as a surface antigen specific for human hematopoietic stem cells [21]. CD133 has been used extensively as a marker for the identification of stem cells from normal and cancerous tissues [22]. The sphere-colony-formation ability and tumorigenicity of $\mathrm{CD} 133^{+}$cells were assayed and reported it could act as a cell surface marker for CSCs in GBC [23]. Chen et al. found that CD133 was significantly up-regulated in GBC tissues. Knockdown of CD133 could inhibit GBC cell migration and invasion. Moreover, knockdown of CD133 led to the inactivation of Akt pathway. Therefore, down-regulation of CD133 inhibits migration of gallbladder carcinoma cells at least partly through reducing Akt phosphorylation. These finding might provide a new insight into gallbladder carcinoma migration [24]. Purified CD133+ gallbladder carcinoma cells are highly resistant to conventional chemotherapy provodes a new mechanism of $\mathrm{As}_{2} \mathrm{O}_{3}$ - induces cell apoptosis and better understanding of drug resistant in gall bladder carcinoma [25].

\section{CD44}

CD44 is an ubiquitous multistructural and multifunctional cell surface adhesion molecule involved in cell-cell and cell- matrix interactions. It is a transmembrane glycoprotein involved in many functions such as cell proliferation, angiogenesis, invasion, and metastasis [26]. CD44 was demonstrated as a first cancer stem cell (CSC) marker to measure the stem cell density of different tumors in the clinics [27]. There are several studies which have evaluated CD44 expression in gallbladder and other cancers, using immunohistochemical (IHC), RT-PCR and southern hybridization (SBH) [28]. Cd44v8-10 expression may be a biological marker for prognostic significance in gall bladder cancer [29]. It was reported that CD44 haplotypes plays an important role with reduced risk of GBC [30]. Study demonstrated that CD44 variant overexpression in patients with gallbladder carcinoma has been linked with histologic dedifferentiation rather than Clinicopathologic factors, including prognosis [31].

\section{ALDH}

Aldehyde dehydrogenases (ALDHs) are a family of enzymes, its activity has been employed as a marker of stem-like cells in many cancers [32,33]. ALDH1expression might be closely related to the carcinogenesis, progression, clinical biological behaviours, and 
prognosis of gallbladder adenocarcinoma [34]. It has been shown that positive ALDH1A3 expression is closely associated with clinical, pathological behavior and poor prognosis of gall bladder cancer [35].

\section{OCT-4}

The Oct-4 gene, a POU- (Pit-Oct-Unc-) domain octamer-binding transcription factor, is a key regulator of self-renewal in embryonic stem cells ${ }^{[36]}$ It has been reported that Oct- 4 is expressed in human tumors but not in normal somatic tissues [37]. Oct- 4 is correlated with decreased survival and might serve as important biological marker for reflecting the carcinogenesis, progression, metastasis, or invasion potential and prognosis of gallbladder carcinoma [38].

\section{CD147}

CD147 (so called EMMPRIN) is a transmembrane protein of the immunoglobulin and may express in many types of tumors. [39,40]. Wu et al. findings suggested that the intensity of CD147 and MMP-2 staining in cancerous tissues is associated significantly with histological types, distant metastasis, and Nevin stages of gallbladder carcinomas. The detection of these two markers combined with cancerous staging may increase the ability of investigators to predict the prognosis of patients with gallbladder carcinomas [41].

\section{CD34}

CD34 expression is considered as a useful indicator/marker in the differential diagnosis of gallbladder clinical features, discriminating patients with primitive gall bladder carcinoma from those with cholelithiasis [42].

\section{SOX}

The SOX (member of the SRY-related HMG-box (SOX) transcription factor family, encodes a protein of 474 amino acids with three distinguishable domains. SOX4, has been demonstrated to be involved in tumorigenesis of many human malignancies [43]. Wang et al for the first time that the over-expression of SOX4 in PGC was significantly correlated with favorable clinicopathologic features and was an independent prognostic factor for better overall and disease-free survival in patients. Therefore, SOX4 might be an auxiliary parameter for predicting malignant behavior for PGC [44]. Yadav et al. OCT-4, SOX-2, and NANOG variants showed an interactive role with treatment response [45].

Advanced GBC has an extremely poor prognosis because of metastasis and identification of metastasis-related biomarkers is essential to improve patient survival. Shi et al. have suggested that ABCG2 might contribute to the chemo resistance of CD44+CD133+ gallbladder cancer cells, and could provide a therapeutic target [46]. EGF and transforming growth factor beta 1 (TGF beta1) plays important roles in tumor biology. NT5E and Fc GBP are key regulators of TGF-1induced epithelial-mesenchymal transition (EMT) and their expression in gallbladder adenocarcinoma act as an independent marker for evaluation of the disease progression, clinical biological behaviours and prognosis [47]. Manohar et al. revelaved that EpCAM+ CD44+ CD13 cells represents the cell population most enriched for clonal self renewal from primary gallbladder also found that CD13, CD227, CD66, CD26 and $\mathrm{CD} 49 \mathrm{~b}$ were differentially expressed between gallbladder and IHBD cells cultured in vitro indicating clear phenotypic differences between the two cell population [48]. Expression of EphB1 and Ephrin-B through immunohistochemical methods for determination of correlations with prognosis could be regarded as independent good prognostic factors and important biological markers for SC/ASC and adenocarcinoma of gallbladder [49]. Novel biomarker candidates including prosaposin and transgelin were validated to be upregulated and downregulated in gallbladder cancer using tissue microarrays and it provide the first large scale proteomic characterization of gallbladder cancer which will serve as a resource for future discovery of biomarkers for gallbladder cancer [50]. Wu et al. demonstrated that the over-expression of ADAM-17 in patients with gallbladder carcinoma has been lined closely with histological grade, pT staging ang prognosis, serve as new target for the treatment [51]. Autocrine TNF- $\alpha$ plays a role as a tumor promoter gene in gallbladder cancer cells, possibly by promoting proliferation and invasion through autocrine mechanisms [52].

Shu et al (2015) demonstrated a significant correlation between high expression of SPOCK1 and poor prognoses of GBC patients, and its oncogene function have been examined further in vitro and in vivo and demonstrated that SPOCK1 acts as a potential oncogene, which in turn contributes to the initiation and progression of GBC [53]. The elevated expression of PEG10 and TSG101 in gallbladder SC/ ASC and adenocarcinoma samples indicates that they are significant markers for progression, clinical biological behavior and prognosis and patients with high PEG10 and TSG101 expression in their tumors are more likely to suffer from invasion and metastatic recurrence [54]. DNA-PKcs and Ku70 are tumor suppressors, and loss of DNA-PKcs and Ku70 expression is an important biological marker for metastasis, invasion, and prognosis of GBC [55]. It has been reported that the aberrant nucleoside levels in the plasma, urine, bile, and tissues served as biomarkers in the diagnosis and these nucleosides may be as useful as biological markers for gallbladder cancer [56]. The positive $\beta 2 \mathrm{M}$ expression or loss of ATP5B expression in tumor tissues is closely related to the metastasis, invasion, and poor-prognosis of gallbladder cancer [57]. Beclin-1, a key modulator of autophagy function, is considered a haploinsufficient tumor suppressor, which has been highly expressed in $\mathrm{GBC}$ and may be an independent predictive marker of favorable prognosis in GBC [58].

\section{Molecular biology of gallbladder cancer}

The advances in molecular biology, results in understanding the genetic basis of cancer. Risk factors responsible for the development of gallbladder cancer, especially gallstone, are associated with several genetic alterations. Genes important for the progression of stem cells, also plays a vital role in the genetic and clinical outcome of cancer. Molecular markers Oct-4, Sox- 2 and nanog variants show its role in the treatment of gallbladder cancer. ALCAM gene polymorphism reported as associated with susceptibility and survival of gallbladder cancer [59]. The positive expression rates of Annexin A3 in gallbladder cancer was reported as significantly higher than that in cholecystitis, with important factor for the initiation and progression of human gallbladder cancer [60].

Loss of E-cadherin expression was high in gallbladder cancer, when compared with cholecystitis and xanthogranulomatous cholecystis cases and its expression might be useful prognostic marker [61]. T-cahderin decreases the expression of Akt3 and phosphorylated Akt molecules, results in down regulation, might inhibit progression of GBC [62].

\section{Conclusion}

Enormous novel approaches to target CSCs have received much attention over the past several years. The rise of the cancer stem 
cell hypothesis provides a new approach to eradicate malignancies. Increasing evidence has suggested that a comprehensive strategy might improve cancer treatments.

\section{References}

1. Gallbladder cancer. Albores-Saavedra J, Henson DE, Klimstra DS, In: Rosai J (2000) Tumors of the Gallbladder, Extrahepatic Bile Ducts and Ampulla of Vater. Atlas of Tumor Pathology. AFIP: Washington: 37-106.

2. Parkin DM, Whelan SL, Ferley J, Teppo L, Thomas DB, et al. (2002) Cancer incidence in five continents. Vol VIII Lyon: IARC IARC Sci. Pub no. 155.

3. He S, Nakada D, Morrison SJ (2009) Mechanisms of stem cell self-renewal. Annu Rev Cell Dev Biol 25: 377-406. [Crossref]

4. Chandross KJ, Mezey E, Mattson MP, Van Zant G (2001) Plasticity of adult bone marrow stem cells. JAI Press: Greenwich CT 2.

5. Slack JM (2000) Stem cells in epithelial tissues. Science 287: 1431-1433. [Crossref]

6. Odorico JS, Kaufman DS, Thomson JA (2001) Multilineage differentiation from human embryonic stem cell lines. Stem Cells 19: 193-204. [Crossref]

7. Franco locatelli (2004) Hoemopoetic stem cell transplantation. 125: 3-11.

8. Reya T, Morrison SJ, Clarke MF, Weissman IL (2001) Stem cells, cancer, and cancer stem cells. Nature 414: 105-111. [Crossref]

9. Al-Hajj M, Wicha MS, Benito-Hernandez A, Morrison SJ, Clarke MF, et al. (2003) Prospective identification of tumorigenic breast cancer cells. Proc Natl Acad Sci USA 100: 3983-3988. [Crossref]

10. Singh SK, Hawkins C, Clarke ID, Squire JA, Bayani J, et al. (2004) Identification of human brain tumour initiating cells. Nature 432: 396-401. [Crossref]

11. Collins AT, Berry PA, Hyde C, Stower MJ, Maitland NJ, et al. (2005) Prospective identification of tumorigenic prostate cancer stem cells. Cancer Res 65: 10946-10951. [Crossref]

12. Ricci-Vitiani L, Lombardi DG, Pilozzi E, Biffoni M, Todaro M, et al. (2007) Identification and expansion of human colon-cancer-initiating cells. Nature 445: 111115. [Crossref]

13. O’Brien CA, Pollett A, Gallinger S, Dick JE (2007) A human colon cancer cell capable of initiating tumour growth in immune deficient mice. Nature 445: 106-110. [Crossref]

14. Eramo A, Lotti F, Sette G, Pilozzi E, Biffoni M, et al. (2008) Identification and expansion of the tumorigenic lung cancer stem cell population. Cell Death Differ 15: 504-514. [Crossref]

15. Prince ME, Sivanandan R, Kaczorowski A, Wolf GT, Kaplan MJ, et al. (2007) Identification of a subpopulation of cells with cancer stem cell properties in head and neck squamous cell carcinoma. Proc Natl Acad Sci U S A 104: 973-978. [Crossref]

16. Chen K, Huang YH, Chen JL (2013) Understanding and targeting cancer stem cells: therapeutic implications and challenges. Acta Pharmacol Sin 34: 732-740. [Crossref]

17. Jaggupilli A, Elkord E (2012) Significance of CD44 and CD24 as cancer stem cell markers: an enduring ambiguity. Clin Dev Immunol 2012: 708036. [Crossref]

18. Lim SC (2005) CD24 and human carcinoma: tumor biological aspects. Biomed Pharmacother 59 Suppl 2: S351-354. [Crossref]

19. Liu B, Zhang Y, Liao M, Deng Z, Gong L, et al. (2011) Clinicopathologic and prognostic significance of CD24 in gallbladder carcinoma. Pathol Oncol Res 17: 45-50. [Crossref]

20. Song SP, Zhang SB, Liu R, Yao L, Hao YQ, et al. (2012) NDRG2 down-regulation and CD24 up-regulation promote tumor aggravation and poor survival in patients with gallbladder carcinoma. Med Oncol 29: 1879-1885. [Crossref]

21. Grosse-Gehling P, Fargeas CA, Dittfeld C, Garbe Y, Alison MR, et al. (2013) CD133 as a biomarker for putative cancer stem cells in solid tumours: limitations, problems and challenges. J Pathol 229: 355-378. [Crossref]

22. Nosrati A, Naghshvar F, Khanari S (2014) Cancer Stem Cell Markers CD44, CD133 in Primary Gastric Adenocarcinoma. Int J Mol Cell Med 3: 279-286. [Crossref]

23. Shi CJ, Gao J, Wang M, Wang X, Tian R, et al. (2011) CD133(+) gallbladder carcinoma cells exhibit self-renewal ability and tumorigenicity. World J Gastroenterol 17: 29652971. [Crossref]

24. Li C, Wang C, Xing Y, Zhen J, Ai Z, et al. (2016) CD133 promotes gallbladder carcinoma cell migration through activating Akt phosphorylation. Oncotarget 7: 17751-17759. [Crossref]
25. Ai Z, Pan H, Suo T, Lv C, Wang Y, et al. (2011) Arsenic oxide targets stem cell marker CD133/prominin-1 in gallbladder carcinoma. Cancer Lett 310: 181-187. [Crossref]

26. Sun JH, Luo Q, Liu LL, Song GB (2016) Liver cancer stem cell markers: Progression and therapeutic implications. World J Gastroenterol 22: 3547-3557. [Crossref]

27. Baumann M, Krause M (2010) CD44: a cancer stem cell-related biomarker with predictive potential for radiotherapy. Clin Cancer Res 16: 5091-5093. [Crossref]

28. Kalekou H, Miliaras DJ (2004) Immuno histochemical study of Microvessel density, cd44 (standard form), p53 protein and c-erbb2 in gallbladder carcinoma. J Gastroenterol Hepatol. 19:812 [Crossref]

29. Yamaguchi A, Zhang M, Goi T, Fujita T, Niimoto S, et al. (2000) Expression of variant CD44 containing variant exon v8-10 in gallbladder cancer. Oncol Rep 7: 541-544. [Crossref]

30. Sharma KL, Yadav A, Gupta A, Tulsayan S, Kumar V, et al. (2014) Association of genetic variants of cancer stem cell gene CD44 haplotypes with gallbladder cancer susceptibility in North Indian population. Tumour Biol 35: 2583-2589. [Crossref]

31. Yanagisawa N, Mikami T, Mitomi H, Saegusa M (2001) CD44 variant overexpression in gallbladder carcinoma associated with tumor dedifferentiation. Cancer 9(2): 408416. [Crossref]

32. Benson DM, Panzner K, Hamadani M (2010) Effects of induction with novel agents versus conventional chemotherapy on mobilization and autologous stem cell transplant outcomes in multiple myeloma. Leuk Lymphoma 51(2): 243-251. [Crossref]

33. Ma I, Allan AL (2011) The role of human aldehyde dehydrogenase in normal and cancer stem cells. Stem Cell Rev 7: 292-306. [Crossref]

34. Liu DC, Yang ZL, Jiang S (2010) Identification of musashi-1 and ALDH1 as carcinogenesis, progression, and poor-prognosis related biomarkers for gallbladder adenocarcinoma. Cancer Biomark 8: 113-121. [Crossref]

35. Yang ZL, Yang L, Zou Q, Yuan Y, Li J, et al. (2013) Positive ALDH1A3 and negative GPX3 expressions are biomarkers for poor prognosis of gallbladder cancer. Dis Markers 35: 163-172. [Crossref]

36. Rosner MH, Vigano MA, Ozato K, Timmons PM, Poirier F, et al. (1990) A POUdomain transcription factor in early stem cells and germ cells of the mammalian embryo. Nature 345: 686-692. [Crossref]

37. Monk M, Holding C (2001) Human embryonic genes re-expressed in cancer cells Oncogene 20: 8085-8091. [Crossref]

38. Yang L, Yang Z, Huang J, Zou Q (2013) PSCA and Oct-4 expression in the benign and malignant lesions of gallbladder: Implication of carcinogenesis, prognosis of gallbladder adenocarcinoma. Biomed Res Int 648420: 9 pages. [Crossref]

39. Saxena DK, Oh-Oka T, Kadomatsu K, Muramatsu T, Toshimori K, et al. (2002) Behaviour of a sperm surface transmembrane glycoprotein basigin during epididymal maturation and its role in fertilization in mice. Reproduction 123(3): 435-44. [Crossref]

40. Xiong L, Edwards CK, Zhou L3 (2014) The biological function and clinical utilization of CD147 in human diseases: a review of the current scientific literature. Int J Mol Sci 15: 17411-17441. [Crossref]

41. Wu W, Wang R, Liu H, Peng J, Huang D, et al. (2009) Prediction of prognosis in gallbladder carcinoma by CD147 and MMP-2 immunohistochemistry. Med Oncol 26: 117-123. [Crossref]

42. Artico M, Bronzetti E, Alicino V, Ionta B, Bosco S, et al. (2010) Human gallbladder carcinoma: Role of neurotrophins, MIB-1, CD34 and CA15-3. Eur J Histochem 54: e10. [Crossref]

43. Sinner D, Kordich JJ, Spence JR, Opoka R, Rankin S, et al. (2007) Sox17 and Sox4 differentially regulate beta-catenin/T-cell factor activity and proliferation of colon carcinoma cells. Mol Cell Biol 27: 7802-7815. [Crossref]

44. Chengguo W, Huadong Z, Jianguo L (2012) Clinopathological significant of Sox4 expression in primary gallbladder carcinoma. Diagn Pathol. 741. [Crossref]

45. Yadav A, Gupta A, Rastogi N, Agrawal S, Kumar A, et al. (2016) Association of cancer stem cell markers genetic variants with gallbladder cancer susceptibility, prognosis, and survival. Tumour Biol 37: 1835-1844. [Crossref]

46. Shi C, Tian R, Wang X, Jiang (2010) CD44+CD133+ population exhibits cancer stem cell-like characteristics in human gallbladder carcinoma. Cancer Biol Ther 10(11): 1182-1190. [Crossref]

47. Xiong L, Wen Y, Miao X, Yang Z (2014) NT5E and FcGBP as key regulators of TGF-1-induced epithelial-mesenchymal transition (EMT) are associated with tumo 
progression and survival of patients with gallbladder cancer. Cell Tissue Res 355(2): 365-374. [Crossref]

48. Manohar R, Li Y, Fohrer H, Guzik L, Stolz DB, et al. (2015) Identification of a candidate stem cell in human gallbladder. Stem Cell Res 14: 258-269. [Crossref]

49. Yuan Y, Yang ZL, Miao XY, Liu ZR, Li DQ, et al. (2014) EphB1 and Ephrin-B, new potential biomarkers for squamous cell/adenosquamous carcinomas and adenocarcinomas of the gallbladder. Asian Pac J Cancer Prev 15: 1441-1446. [Crossref]

50. Sahasrabuddhe NA, Barbhuiya MA, Bhunia S, Subbannayya T, Gowda H, et al. (2014) Identification of prosaposin and transgelin as potential biomarkers for gallbladder cancer using quantitative proteomics. Biochem Biophys Res Commun 18 446(4): 863-9 [Crossref]

51. Wu K, Liao M, Liu B, Deng Z (2011) ADAM-17 over-expression in gallbladder carcinoma correlates with poor prognosis of patients. Med Oncol 28: 475-480. [Crossref]

52. Zhu G, Du Q, Wang X, Tang N, She F, et al. (2014) TNF- $\alpha$ promotes gallbladde cancer cell growth and invasion through autocrine mechanisms. Int J Mol Med 33: 1431-1440. [Crossref]

53. Shu YJ, Weng H, Ye YYn (2015) SPOCK1 as a potential cancer prognostic marker promotes the proliferation and metastasis of gallbladder cancer cells by activating the PI3K/AKT pathway. Mol Cancer 14: 12. [Crossref]

54. Liu Z, Yang Z, Liu D, Li D, Zou Q, et al. (2014) TSG101 and PEG10 are prognostic markers in squamous cell/adenosquamous carcinomas and adenocarcinoma of the gallbladder. Oncol Lett 7: 1128-1138. [Crossref]
55. Ren F, Yang ZL, Tan X, Liu D, Zou Q, et al. (2014) DNA-PKes and Ku70 are predictive markers for poor prognosis of patients with gall bladder malignancies. Appl Immunohistochem Mol Morphol 22: 741-747. [Crossref]

56. Letelier P, Riquelme I, Hernández AH, Guzmán N (2016) Circulating MicroRNAs as Biomarkers in Biliary Tract Cancers. Int J Mol Sci 17. [Crossref]

57. Sun J, Yang ZL, Miao X, Zou Q, Li J, et al. (2015) ATP5b and $\beta 2$-microglobulin are predictive markers for the prognosis of patients with gallbladder cancer. $J \mathrm{Mol} \mathrm{Histol}$ 46: 57-65. [Crossref]

58. Park JY, Kim HS, Cho H, Kim NC, Chae KH, et al. (2014) Clinicopathologic correlation of autophagy-related Beclin-1 expression in gallbladder cancer. Hepat ogastroenterology 61: 1494-1500. [Crossref]

59. Yadav A, Gupta A, Rastogi N, Agrawal S, Kumar A, et al. (2016) Association of cancer stem cell markers genetic variants with gallbladder cancer susceptibility, prognosis, and survival. Tumour Biol 37: 1835-1844. [Crossref]

60. Tan Y, Meng HP, Wu Q, Wang FQ, Wu HR, et al. (2010) [Proteomic study of gallbladder cancer, with special reference on the expression and significance of annexin A3. Zhonghua Bing Li Xue Za Zhi 39: 382-386. [Crossref]

61. Priya TP, Kapoor VK, Krishnani N, Agrawal V, Agrawal S, et al. (2010) Role of E-cadherin gene in gall bladder cancer and its precursor lesions. Virchows Arch 456 507-514. [Crossref]

62. Adachi Y, Takeuchi T, Nagayama T, Furihata M (2010) T-cadherin modulates tumorassociated molecules in gallbladder cancer cells. Cancer Invest 28:120-6. [Crossref]

Copyright: $@ 2017$ Srivastava AN. This is an open-access article distributed under the terms of the Creative Commons Attribution License, which permits unrestricted use, distribution, and reproduction in any medium, provided the original author and source are credited. 